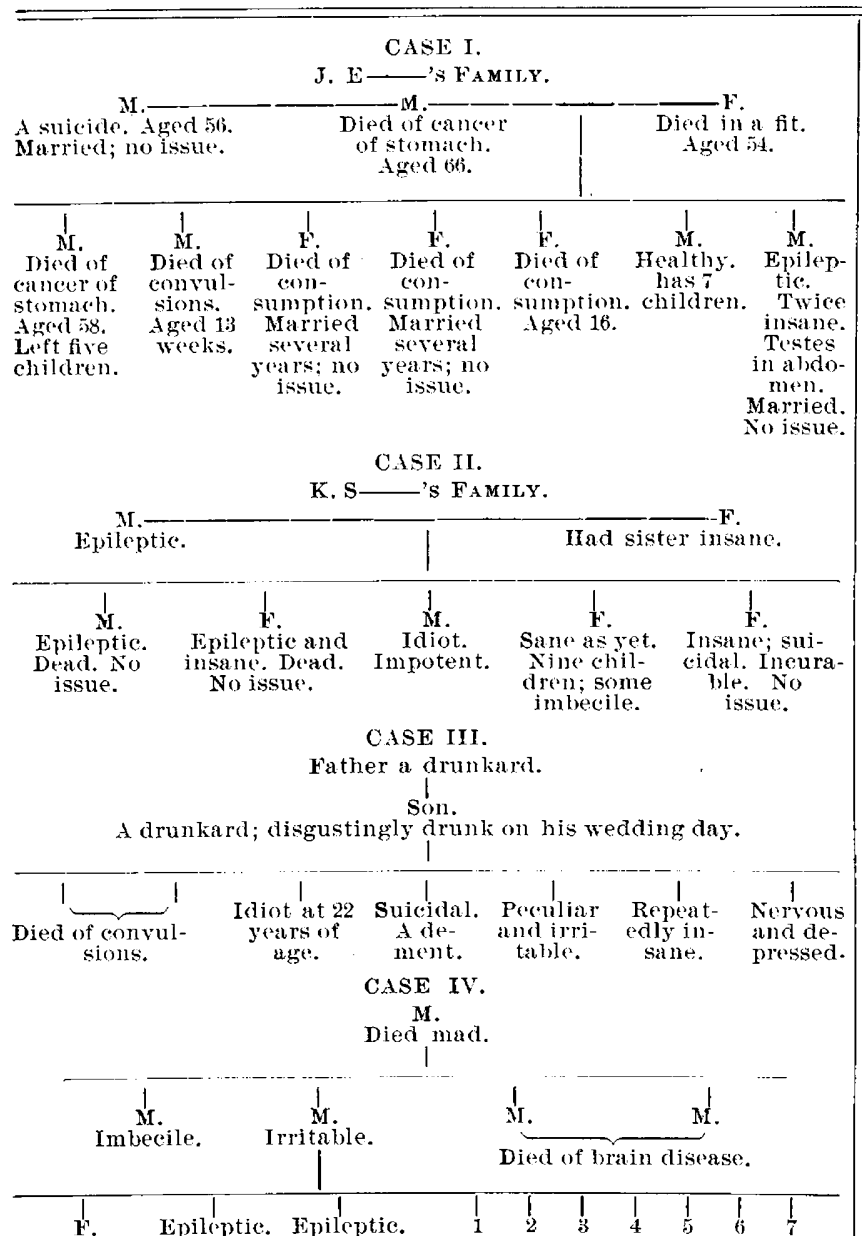

Imbecile.

Epileptie. Epileptic.

All seven died in convulsions.

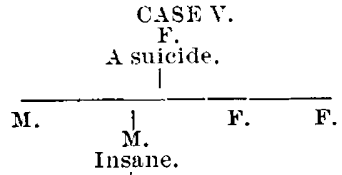

CASE VI. Mute.

I

Excitable. Dúl. Epileptic.

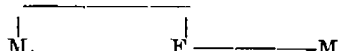

Mute. No Normal.

issue.

f. $\frac{1}{\mathrm{l}}$ M. $\quad$ M. Sormal. I Normal.

Mute.

J. G. A—'S FAMILY HISTORY.

Paternal side.

Grandfather, a drunka

Uncle, a drunkard.

Uncle, a drunkard.

Uncle, an epileptic.

table.

Maternal side;

Grandfather. "inormal.

Encle, epileptic.

Uncle, rheumatic, total cripple and his daughter also.

Encle, rheumatic.

Mother, died in an asylum.

Daughter, has had Son, now insane.

3d Gen. $\left\{\begin{array}{l}\text { Son, died a few days old of convulsions. } \\ \text { Son }\end{array}\right.$

Daughter, suicidal melancholiac; died in an asslum; no issue, Family extinct.

CASE VIII.

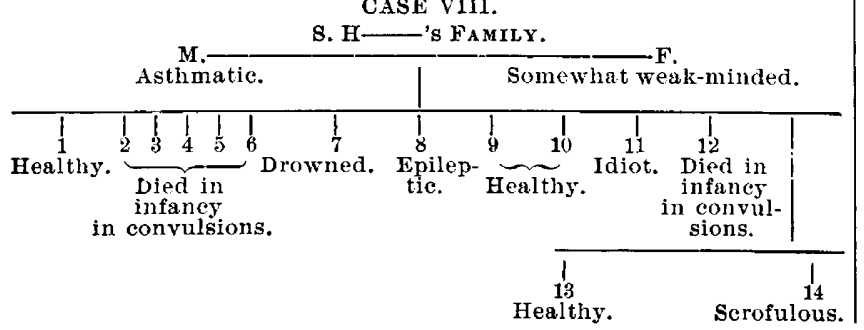

FATHER.

Ecentric, hypochondriac.

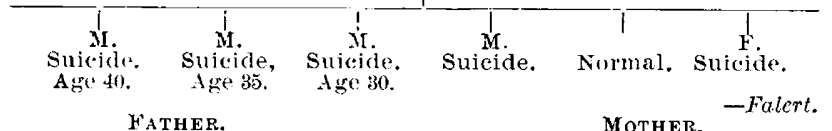

Melancholia; died insane, Nervous, emotional.

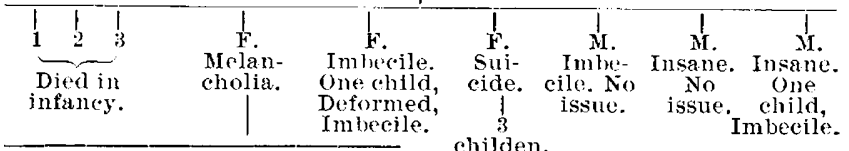

\begin{tabular}{|c|c|c|c|c|}
\hline \multirow[t]{2}{*}{$\begin{array}{c}1 \\
1-5 \\
\text { Die in } \\
\text { Infancy. }\end{array}$} & $\begin{array}{c}1 \\
6 \\
\text { Insane. }\end{array}$ & $\begin{array}{c}1 \\
\text { Eccen- } \\
\text { trie. }\end{array}$ & & $\begin{array}{l}\text { cmiden. } \\
\text { 1. Imbecile. } \\
\text { 2. Dies of apoplexy. } \\
\text { 3. An artist. }\end{array}$ \\
\hline & & & 8 & 9 \\
\hline
\end{tabular}

-Dontrebertb.

Marry. No issue.

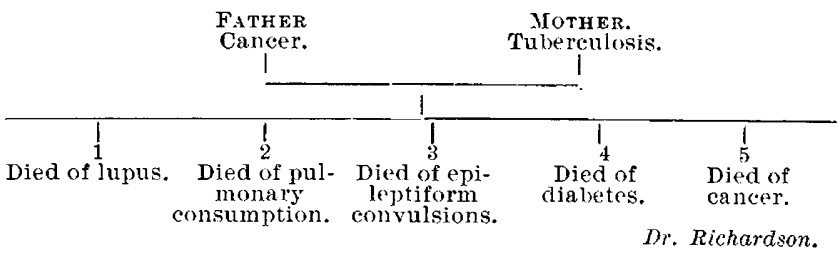

In the midst of these overwhelming exhibits, surely the welfare of the community demands that marriage should be regulated. It is horrible to contemplate what will be the condition of the race in the future, and what will become of our social and political institutions if this wholesale production of abnormalities does not cease.

In most of the States of the Union a marriage license is necessary before the ceremony can be performed, but its requirements are insignificant. Let us agree that in addition, proper evidence must be furnished that both parties are in good health, that they are not insane, criminals, paupers, alcoholic nor narcotic inebriates, that they are not tuberculous, cancerous nor epileptic, and that they have not active venereal disease.

If the members of this great profession will unitedly advocate this great reform, they will succeed, and more than ever deserve the title of public benefactors.

\section{AGE AND SEX INCIDENCE OF MORTALITY IN MICHIGAN FROM DIPHTHERIA AND FROM CROUP DURING TWENTY-FIVE YEARS, 1870-94; A STATIS. TIC STUDY.}

Read by title in the Section on State Medicine, at the Forty-seventh Anuual Meeting of the American Medical Association, at Atlanta, Ga., May 5-8. 1896.

BY CRESSY L. WILBUR, M.D.

DIVISION OF VITAL STATISTICS, DEPARTMENT OF STATE, LANSING, MICH.

No apology is necessary at the present time for a statistic study bearing upon the history of diphtheria and croup in the United States during recent years. It is only a short time since the etiologic characteristics of the disease, or diseases, dependent chiefly upon the presence of the Klebs-Löffler bacillus and associated microörganisms, have been definitely ascertained, and a still briefer time has elapsed since the antitoxin treatment, based entirely upon modern bacteriologic research, has promised to revolutionize entirely the treatment, and to greatly reduce the mor. 
tality of this, by far the most fatal acute infectious disease prevalent in this country, or at least its northern part.

It is of especial importance, therefore, in order that it may be known whether the claims of the new method of treatment are substantiated by experience, that reliable statistics of immediately preceding periods be available for comparison, and in case the employment of the serum therapy in any given locality appears to be attended with a reduction in the death rate from diphtheria, that it be known whether such reduction was probably caused by the special measures employed, or whether a reduction in mortality was reasonably to be expected as a consequence of the periodic fluctuations characteristic of the history of this and most other epidemic diseases.

Usually on the introduction of a new remedy, the appeal is primarily to the results of hospital treatment. This was necessarily so in the present instance, as the curative serum was costly and difficult to be obtained at first by general practitioners. Later, with increased facilities for its production and the undertaking of its preparation by official agencies, its use was more generally diffused, and an appeal could be fairly made to the testimony of the mortality statistics prepared by the general registry offices. Hospital statistics are notoriously unreliable, it being often impracticable to eliminate or fully describe the selective influences that determine the characters of patients and the results of treatment, as well as the preliminary diagnoses upon which the statistic conclusions largely depend. Small numbers are also usually employed, iri themselves a frequent source of fallacy. In the deductions drawn from general mortality statistics, on the other hand, these minor sources of error tend to neutralize one another, so that any marked change from the usual course of a disease may, with considerable certainty, be ascribed to some extraneous influence.

Purpose of the present paper. - The data contained in the present paper are not presented in the interest of any particular method of restriction or prevention of diphtheria, nor, primarily, to illustrate the value of the antitoxin or any other method of treatment. If the serum therapy shall prove to be of as great usefulness as at present appears likely, valuable evidence as to its efficacy will probably be derived from the comparison of the incidence of mortality by sex and periods of age, as presented in this paper, for Michigan for the pre-antitoxin period, with corresponding data to be tabulated later for the "antitoxin era." If the antitoxin method goes the way of the Bergeon, Koch's tuberculin and other "fads," nevertheless the evidence here presented may be of special interest to the sanitarian and to all students of State medicine, from its bearing upon the history and success of the methods of prevention and restriction of diphtheria advocated and carried out by the Michigan State Board of Health under the able direction of Dr. Henry B. Baker. In any event it seemed to me that an impartial account of the prevalence of diphtheria in Michigan, and one as accurate as the available statistics would permit, would be of service in advancing our knowledge of this disease.

As indicated by the title, the discussion is confined entirely to the presentation of two features, with their inter-relations, of the mortality in Michigan from diphtheria and croup, viz., the distribution by ages in periods of years and by sexes of the decedents. It will be necessary to preface the subject proper with some general account of the history of diphtheria in Michigan as a whole, and its relation to the recorded mortality from this cause in other States and countries, in order that the position of Michigan in reference to the disease may be understood. Other important features of the recorded mortality are purposely excluded from the present discussion, e.g., the geographic distribution through the State, ${ }^{1}$. relative death rates of rural and urban populations, and monthly and seasonal prevalence, with relations to meteorologic conditions.

The study will chiefly show: 1 , the availability of mortality statistics known to be imperfect in certain directions for use in certain other directions, as evidenced by the constancy and clearness of their testimony; 2, the characteristic differences in the age and sex incidence of diphtheria and croup, and, inferentially, the inexpediency of confusing their statistics under the term "diphtheria and croup" from a statistic point of view; 3 , the desirability of ascertaining the causes, and so far as practicable, of preventing the increased relative mortality from diphtheria of female children on reaching the age of five years and upward.

Source and character of ata.-The Registration Reports of Michigan are utilized as the source of information. This series of annual reports began April 5, 1867, and is continued at the present time in substantially the same form that it oripinally assumed. The method of collection of data is imperfect, being nearly the same as that of the United States census in non-registration States, $i . c$., an enumeration of the facts some time after their occurrence. Many deaths fail to be registered each year, and the deaths in months near the date of enumeration are more thoroughly collected than those of months more remote from it. The result is precisely as in the case of the United States census mortality statistics of non-registration States, that study of the monthly and seasonal prevalence of mortality is entirely misleading, unless a graduated "correction" be applied to the monthly returns, something nearly or quite impossible to satisfactorily accomplish ${ }^{2}$ and, secondly, that the absolute rates for the year, both of aggregate mortality and of individual causes, are considerably below the truth. For the latter imperfection it has been necessary to make an approximate estimate, since otherwise we should have no means of judging of the relative mortality of the State as compared with other States and countries. In the Registration Reports of suncessive years up to the year 1890, amounts of deficiency, different for each year, have been calculated, varying from 66.24 per cent. down to 9.92 per cent. of the original returns, and giving an average "correction" of about 40 per cent." There has been, however, no evidence whatever to show that the accuracy of registration has been any greater in one year than in another; indeed, the only condition of usefulness of the data presented, as employed for comparison of mortality in successive years, involves the assumption that the degree of imperfection of registration remained substantially the same from year to year.

For geographic distribution, see Michigan Registration Report for 892, map opposite p. 195; the period is one of five years, 1888 to 1892 , and iphtheria and croup are taken as one disease. See also the maps of diphtheria and croup (separately) in the Mortality and vital statistics Report of the Ter th census, in which,

2 See Mortality and Vital Statistics of the Tenth V. S. Census, Part I, $\mathrm{xl}$.

3 iflch. Reg. Rep., 1891, p. 132 
This is the assumption under which the vital statistics of successive United States censuses are compared, and is, in fact, even more tenable as regards the Michigan statistics, since they have been collected under an unaltered law and by precisely the same registration machinery, at least since 1869 . For this reason the writer has rejected the variable "correction" formerly employed in the reports, and has substituted since 1891, and employs in the present paper, an estimation-a mere guess, somewhat qualified by study of actual registered death rates of certain Michigan cities, and knowledge of the general rate of mortality of similar populations-that the returns of deaths in Michigan should be increased by about 60 per cent. to give the actual deaths that occurred. This estimate is probably sufficiently low, corresponding to an increase of the registered mortality from about 10 per 1,000 to an estimated actual mortality of about 16 per 1,000 population; is applied uniformly to successive years, and to the subdivisions of population, by sex, periods of age, etc.; and is only applied when the Michigan statistics are brought into relation with approximately correct rates of registration States or countries for direct comparison. For study of the course of mortality, the uncorrected rates, if only the assumption of their substantial. uniformity of inaccuracy be granted, are as reliable as more complete ones.

Having stated the chief respects in which the Michigan statistics can not be taken at their face value, viz., monthly and seasonal distribution of mortality and absolute death rates, the following points upon which the results obtained from the Michigan returns are probably fully correct and reliable may be stated: 1 , relative mortality from all causes and from special causes of death in successive years - the latter subject to the usual criticisms dependent upon defective diagnosis; 2, geographic distribution of mortality through the State; 3, proportions of deaths from specified causes to total mortality - this, however, a discredited ratio in vital statistics, although much used in the United States census reports in default of a better; 4 , incidence of mortality by sex; 5 , incidence of mortality by age. It is with the two latter features that the present paper is specially concerned, and it should be clearly understood that the admitted deficiency of Michigan registration in certain particulars in no wise affects the indications drawn from a large and fully representative mass of returns in regard to the facts of age and sex incidence of mortality from diphtheria and croup.

Statistic nomenclature and classification of diph. theria and croup.-The statistic study of a disease is necessarily secondary, in point of time, to its clinical study. It follows that uncertainty in diagnosis, confusion as to the true clinical and etiologic characters of a disease, or confusion of one disease with another, will be reflected in the vital statistics subsequently collected. The advances of knowledge in methods of exact diagnosis are shared, first, by the most progressive members of the medical profession, or possibly, by specialists in certain fields of investigation, in whose particular lines of research the advances were made; second, the rank and file of the profession adopt the discovery and it becomes a part of ordinary professional opinion; and lastly, the new knowledge filters through medical opinion and is more or less rapidly and thoroughly disseminated by the press until it finally becomes a part of the common belief of the people. It is from the people themselves, as a rule without the immediate intervention of professional opinion, that the data in regard to causes of death are collected in Michigan, and the foregoing considerations are given in explanation of the facts that they are apt to be somewhat indefinite in character and, further, that the returns of any year do not correspond to the latest professional knowledge of the time. There is in this an advantage, however, that the returns are not affected by the more transient waves of medical thought, but only by those deeper currents representing well-grounded changes in medical belief.

The vital statistics of Michigan do not extend back, by about ten years, to the time of the first general recognition of diphtheria in this country. It is probable that substantially the same clinical distinctions between diphtheria and croup have existed during the entire twenty-five-year period. The early confusion between diphtheria and croup, prior to the recognition of the "new disease," such as appears in plain evidence in the death rates of Chicago (Table 2), had been outgrown, and the recent tendency to report deaths from what would have formerly been considered "croup" or "membranous croup," as diphtheria pure and simple, has probably not affected the statistics to a very great extent, although it may be expected to show a marked influence in the next few years.

Bacteriologic analysis, by its proof of the KlebsLöffler bacillus as the cause of true diphtheria, has laid the foundation of future exact statistics of this and related diseases. But we should not allow our statistic methods to outrun the actual advance of knowledge. While on the one hand, there is undoubted evidence that many cases of croup are diphtheritic in character and due to the infection of the Klebs-Löffler bacillus, it is equally positive that a certain proportion of them are not diphtheritic. Indeed, a certain fairly large proportion of cases of clinical diphtheria is found to be lacking in the presence of the essential germ, under our present methods of recognition, while in the undoubted cases of true diphtheria the action of the Klebs-Löffler bacillus is modified so largely by the presence of other species of microörganisms that the tendency is undoubtedly, at present, in the direction of a more minute analysis of true diphtheria, rather than to the inconsiderate consolidation of diseases possessing quite distinctive clinical, etiologic and statistic characters. Professor Novy of the University of Michigan well remarks, "That which for clinical or anatomic reasons is described as a definite disease, may in reality be far from be an entirety. . . . What was called a disease becomes, through the study of its etiology, a group of diseases. The old typhoid fever has passed through such a history, and we may say in advance that diphtheria has recently experienced a similar development.",

In the older Farrean classification of causes of death, as employed at present in the Massachusetts and Rhode Island Registration Reports, and in the Michigan Registration Reports up to the year 1892, diphtheria and croup are placed together, but separately, among the zymotic diseases. In the later classification adopted by the Registrar-General of England, and which is in use in most of the English colonies and in certain States of this country, croup

4 Etiology of Diphtheria, Trans. Mich. State Med. Soc., 1884, p. 396. 
is removed from its position in conjunction with/compiled under diphtheria. So also are included diphtheria, and placed among the diseases of the under the latter head a few cases of "putrid sore respiratory system under the class of local diseases. throat" occuring during the early years of registraThis was undoubterly a mistake, although made with tion.

the sanction of the Royal College of Physicians at the General prevalence of diphtheria and croup in time (1883), for recent bacteriologic evidence makes Michigan.-Two tables are given in illustration of it clear that a large proportion, perhaps at least 75 this subject, which show respectively the general per cent., of cases of croup is in reality diphtheritic. importance of diphtheria as a cause of death during The distinction made by the Italian reports ${ }^{5}$, which recent periods of years in certain European countries, place "difterite (crup difteritico ed altre forme difter- Australasian colonies, and in the United States; and iche)" under the head of infectious diseases, while the course of diphtheria and croup as registered year "crup non difteritico" is put under the head of dis- by year in Michigan, compared with Chicago, Massaeases of the respiratory organs, would be valuable, chusetts, England and Wales, and the colony of were it not certain, in the light of our present bacter- Queensland.

iologic knowledge, that the practical distinction of non-diphtheritic from diphtheritic croup must have been quite impossible at the time this classification was adopted. The tendency at present, as evidenced by many European (continental) reports, and some in this country, is to combine the mortality reported from diphtheria and croup under one title, namely, diphtheria and croup, or simply diphtheria. Bertillon says, referring to his proposed statistic nomenclature of causes of death, which was presented to the International Statistical Institute, Chicago, 1893:" "It is very important for exactness of international comparison that the titles 'diphtheria' and 'croup' should always be placed side by side to facilitate adding the numbers; we prefer to combine them under a single title." This latter preference I can not but regard as unfortunate for the reason that such statistics of diphtheria and croup cease to be comparable with those of diphtheria and croup stated separately, as found in all reports following the present Registrar. General's classification. An even worse method, considered statistically, however justifiable it may be from the present bacteriologic and from a sanitary point of view, is the plan boldly adopted in the Chicago report for the year 1894 , of adding bodily 80 per cent. of the reported deaths from croup to diphtheria. The rates thus changed become wholly incomparable with those of previous years, which should have been either changed in a similar manner, or, better, an additional column showing the aggregate mortality from diphtheria and supposed diphtheritic croup might have been given. "It is not the duty of a statistic office to interpret diagnosis (that is to say, to guess at what has been left incomplete). It can only register facts as they are formulated." (Bertillon.)

In the provisional classification of causes of death employed in the Michigan Registration Reports since 1892, I have placed the returns of diphtheria, croup and membranous croup side by side, in order that the summation or total deaths from diphtheria and croup, might be readily obtained, while at the same time the statistic integrity of each cause of death, as returned, remained unimpaired. The aggregate number of deaths registered during the twenty-five years from diphtheria and croup was 28,088 , of which number there were 21,095 deaths reported as diphtheria, 5,897 as croup (otherwise unspecified) and only 1,096 as membranous croup. The very few cases returned as spasmodic croup are included under simple croup, while a few returned as diphtheritic croup have been

亏Elenco systematico delle cause di Morte, Statistica delle cause d Morte. $18 \times \bar{y}$, p. LluI.
6 Trunsluted and anpended to Keport of Committee on Nomencla. ture and Forms of Vital Statistics made to the American Public Health ture and Forms of Vitalion, Montreal, 1894.

\begin{tabular}{|c|c|c|c|}
\hline \multirow[b]{2}{*}{ Country, State or City. } & \multirow[b]{2}{*}{ Years. } & \multicolumn{2}{|c|}{ Rate per 100,000 population. } \\
\hline & & Diphtheria. & $\begin{array}{l}\text { Diphtheria } \\
\text { and Croup. }\end{array}$ \\
\hline \multicolumn{4}{|l|}{ Europe. } \\
\hline$\cdots \cdot \ldots$ & $188 \bar{i}-91$ & & 132.0 \\
\hline Belgium.. & $1 \times 87-91$ & & 57.7 \\
\hline England and Wales. & $1887-91$ & 17.4 & 29.1 \\
\hline London & $1897-91$ & 32.3 & \\
\hline France (cities) & $1887-91$ & 66.6 & 24.9 \\
\hline Germany (cities) & $\begin{array}{l}1857-91 \\
1890\end{array}$ & & $\begin{array}{r}102.1 \\
92.0\end{array}$ \\
\hline 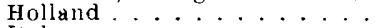 & $1987-91$ & 14.5 & $\begin{array}{l}92.0 \\
36.6\end{array}$ \\
\hline . . . . . & $1887-91$ & 60.8 & 70.5 \\
\hline...... & $1887-91$ & 7.6 & 23.7 \\
\hline 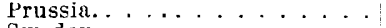 & $188 \bar{i}-91$ & & 141.7 \\
\hline 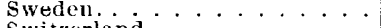 & $1887-91$ & 38.9 & 52.0 \\
\hline Switzerland. Australnsia. $\cdots \ldots$ & $1887-91$ & & 35.3 \\
\hline New South Wales...... & $1878-87$ & & 47.7 \\
\hline New Zealand. . . . . . . & $1878-87$ & & 24.2 \\
\hline 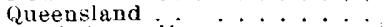 & $1878-87$ & & 47.5 \\
\hline South Australia. . . . . . & $1878-87$ & & 59.3 \\
\hline Tasmania. . . . . . . & $1878-87$ & & 44.6 \\
\hline Victoria.. & $1878-87$ & & 41.7 \\
\hline United States,registrationstates & 1890 & 63.0 & 90.4 \\
\hline Cities, 28 over 100,000 pop.. & 1890 & & 116.6 \\
\hline II assachusetts. . . . . . & $1896-90$ & 61.6 & 85.0 \\
\hline Baltimore . . . . . . & $1885-90$ & & 80.1 \\
\hline Bostou. & $1885-90$ & & 124.5 \\
\hline Brooklyn. & $1885-90$ & & 164.4 \\
\hline New York ........ & $1 \times 85-90$ & & 181.6 \\
\hline Philadelphia....... & $1885-90$ & & 98.3 \\
\hline Wushington... & $1885-90$ & & 59.6 \\
\hline Chicago & $1885-89$ & 119.9 & 170.7 \\
\hline$\ldots 1$ & $1890-94$ & 72.7 & 100.3 \\
\hline Detroit $\ldots$ & $1890-94$ & & 164.0 \\
\hline Grand Rapids & $1890-94$ & & 100.3 \\
\hline Michigan, as returned.... & $1885-89$ & 47.4 & 67.8 \\
\hline Hichigan, as returned. . . & $1890-94$ & 45.6 & 50.3 \\
\hline Michigan, as estimated. . & $1885-89$ & 75.8 & 108.5 \\
\hline Michigan, as estimated. & $1890-94$ & 73.0 & 94.9 \\
\hline
\end{tabular}

Noтf.-The data for Europe are from the statistica delle Cause di Morti, Rome, 1s94. and bave been kindly revised by Prof. Richmond MayoSmith of Columbia College, from whose work, Statistics aud Sociology they were taken. The rates for Australasia are as given in the Victorian Year Book, 1894. The rates for the American cities during the six-year period, 1885-90, are from the special investigations of the Eleventh U.S. Census. The rates from diphtheria for Chicago are the means of the rates stated for the five-year periods in the valuable "Chronological
Summary of Chicago Mortality, 1851-1894," forming a part of the Annual Report of the Department of Health for the year 1994. In obtaining the rates for croup from this Summary the writer nearly fell into erro from the fact that the column in the statistics of this disease (p. 250) corresponding in position to the column of death rates per 10,000 popu lation in all of the other tables, does not contain death rates, as stated by the general heading. but instead contains "percentages of total deaths;" it was necessary to calculate all of the rates given for croup in Table 2 , and from these annual rates the means given above were obtained. For the Michigan cities, Detrott and Grand Rapids, reference was made to the table in the Michigan Registration Report, 1893, p. 248, the rates in which were based upon the deaths actually registered by the
city health officers, and recorded in their monthly or annual reports.

Table 1 indicates the world-wide extension and universal importance of diphtheria as a cause of death. Incidentally it shows the inconvenience in

7 Cape Colony has only just adopted a general registration system (Act of 13th July, 1894), so that data representative of Africa are no available. It may be noted, however, for certain cities and towns of Cape Colony the death rates from "diphtheria and croup" in 1894 wer extremely high: Cape Town, 80.4; King William's Town, 83.0: Worces ter, 92.5 ; Malmesbury, 162.5 ; Beaufort West, 179.1 : Murraysburg. 382.8 Aberdeen, 398.4 , all rates per 100,000 population. The antitoxin treatment has come into general use, serum being supplied to medical men
cost.-Cape of Good IIope Reports on the Public Health, 1894, p. xxiv. 
making comparisons arising from the fact that for some croup, are indicative of the confusion between these countries and cities rates for diphtheria only, in others diseases which was present at its first outbreak. Until for diphtheria and croup only, could be obtained. We about 1875 croup had caused a larger annual mortality notice that England and Wales, Ireland, Holland and in Chicago than diphtheria as a rule, but since that Switzerland, show a low mortality as compared with time diphtheria has been the more fatal. It should other countries of Europe, that the prevalence in be remembered that for 1894 the compiler of the Australasia is light compared with Europe and Amer- Chicago statistics has taken 80 per cent. of the regisica, and that the mortality in America is very high as tered mortality from croup and added it to diphtheria, a rule. The rates for the twenty-eight largest cities of thus disturbing the true relations of these causes of the United States, Germany and England, are from death as returned.

the report made to the Eighth International Congress Massachusetts was selected as a State fairly repreof Hygiene and Demography, Budapest, 1894, by the sentative of the East, and because her system of American Committee on Diphtheria, whose chairman registration is the oldest and probably the most perfect was Dr. J. S. Billings, ex-Deputy Surgeon-General of any in this country. The data are from the RegisU. S. Army, editor of the "Vital Statistics Reports of tration Report of 1890, the rates having unfortunately the Tenth and Eleventh U. S. Censuses," and the not been continued in later reports.

foremost American authority on the subject.

TABLE 2.-Course of mortality from diphtheria and from croup-annual Massachusetts, England and Wales, and Queensland.

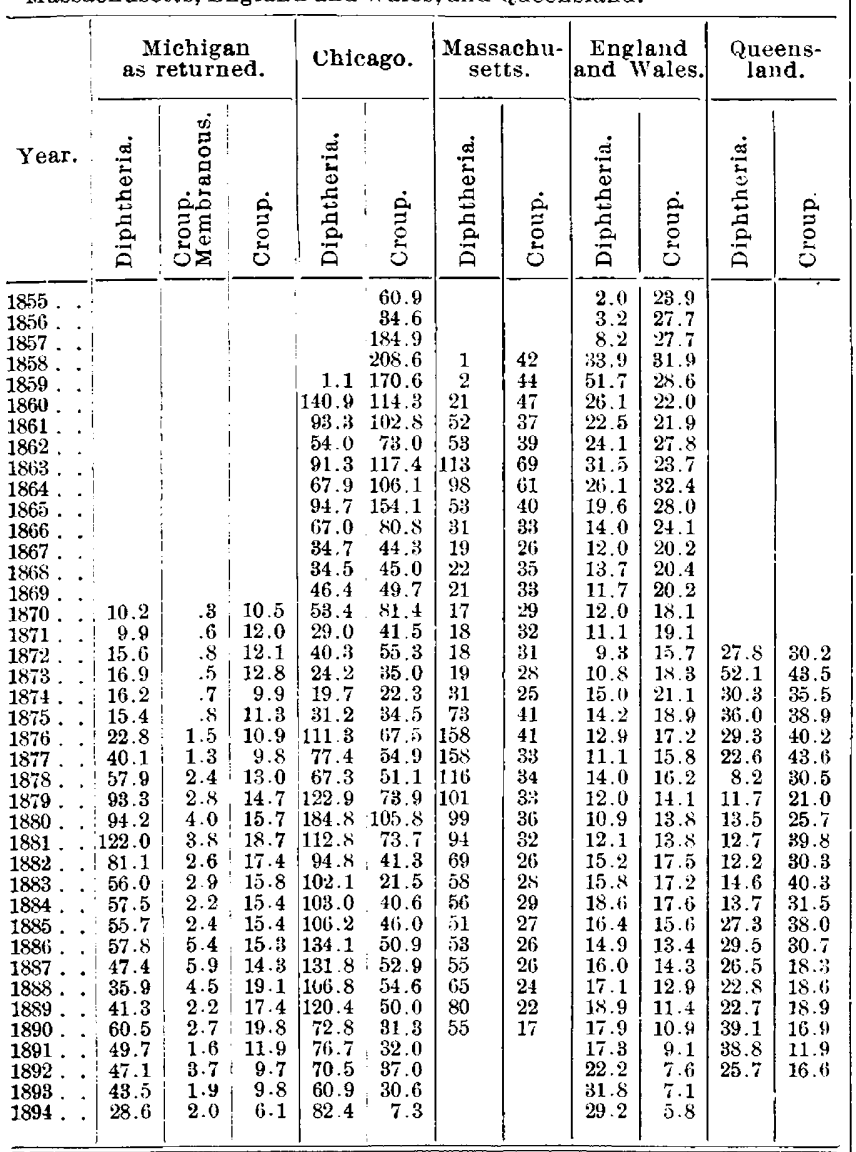

In Table 2 the fluctuations, but not the absolute rates, of the mortality in Michigan from diphtheria and croup may be compared with corresponding rates for Chicago, Massachusetts, England and Wales, and Queensland for successive years. These comparative data are chosen for their special significance. The course of the disease in Chicago, from its geographic proximity, may be taken as corresponding fairly closely to that in Michigan, but it extends over a longer series of years, in fact from beyond the first recognition of the disease diphtheria as such during the present period of prevalence. The high death rate from "croup" in 1858 and 1859, during which years practically no "diphtheria" was reported, together with the high death rate from diphtheria in 1860 attended with some decline of the rate from
Besides the rates given for England and Wales as representative of European statistics of diphtheria, it would have been desirable to present a corresponding series for Germany or some other continental country, in which the disease is far more prevalent, as a rule, than in England. Unfortunately statistics were not at hand for this comparison, so that the general relations indicated in Table 1 can only be referred to as illustrative of the general European mortality from this disease.

The data for Queensland, which colony was taken as fairly representative of Australasian experience, do not extend back as far as would be desirable in order to show the early development of diphtheria as a cause of death in the Southern Hemisphere. They were, however, the longest series of death rates accessible to the writer, and have been taken directly from the annual reports of the Registrar-General of that colony. A complete file of the annual reports of New South Wales, beginning with the year 1857 , completely covers the history of the disease, but, unfortunately, for the early years of registration the zymotic diseases are all grouped together, without stating separately the number of deaths due to each cause. The first mention of diphtheria occurs in the Report for the year 1864 , but the disease had occurred to some extent during previous years, and had been tabulated as quinsy. An interesting table is given in the 9th Annual Report for 1865 showing the deaths annually registered from certain diseases during previous years, part of which is here given:

Deaths registered in New South Wales, $1856-64$.

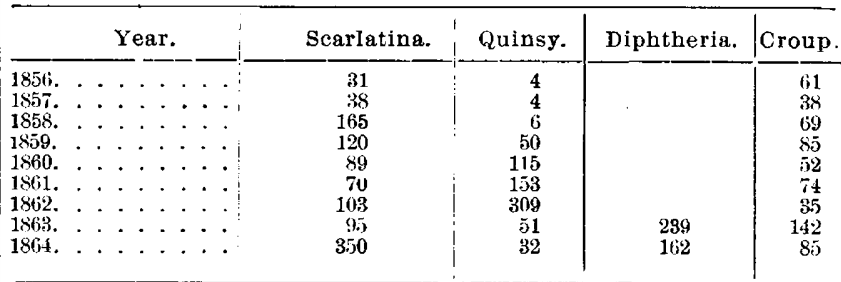

General age and sex incidence of diphtheria and croup in Michigan during the twenty-five-year period, 1870-94.-In Table 3 are given the condensed results of registration for twenty-five years as regards these particulars. About 85 per cent. of all decedents from croup were under five years of age, and about 13 per cent. were aged from $\tilde{5}$ to 9 years. The proportions at more advanced age periods were insignificant. From diphtheria a smaller percentage of deaths occurred under 5 years of age ( 46.3 pèr cent. for males, 42.1 per cent. for females), about one-third of the total deaths was at the period of 5 to 9 years, 
while the period 10 to 14 showed about the same proportion of deaths from diphtheria as the preceding quinquennial period did from croup. Nearly 8 per cent. of all deaths from diphtheria were of persons over 15 years of age.

The death rates per 100,000 mean population from croup are much less than those from diphtheria at every period of age except the first (0-4); the greater concentration of deaths from croup into this period raises the rate of mortality from croup to over 50 per cent. of that from diphtheria.

As regards sex, the marked distinction will be noted that croup causes more deaths of males, diphtheria more deaths of females. Comparing the death rates at each age period by sex (and thus eliminating the unequal distribution of the sexes in the population, which would affect the results if the numbers of deaths of each sex were only compared), we find that the proportion of death rates of males is higher than that of females for croup at all ages and during the quinquennial age periods, $0-4,5-9,15-19$. For the period 10 to 14 a lower rate appears for males, while for ages over 20 years the rates are equal. There were only 102 deaths returned from croup over 10 years of age, so that the proportions above the first two periods of age should probably be rejected from insufficiency of data. Except for the first five-year period, during which the death rates of each sex are nearly the same, with a slight excess of males, diphtheria shows a markedly greater fatality among females. From 5 to 9 years of age about eighteen males die for every twenty females; from 10 to 19 about seventeen males to every twenty females, and above 20 years of age the disproportion is still greater, being at the rate of only about thirteen males to twenty females.

In both age and sex incidence, membranous croup is seen to occupy an intermediate position between croup, returned only as such, and diphtheria. Contrary to what might have been expected, the proportions, both by sex and age, appear to stand in somewhat closer relation to those of croup than to those recorded for diphtheria. It is therefore obvious that in the statistic treatment of deaths returned from "membranous croup," consolidation with croup is more desirable than consolidation with diphtheria, provided the apparent distinction between these two latter forms of return is to be maintained. This position leaves open the question as to whether all deaths from croup are not largely diphtheritic, the peculiar age and sex incidence of the former being due to clinical distinctions not borne out by bacteriologic criteria.

In any case, from the small number of deaths reported from membranous croup, we shall be justified in neglecting this item, and referring chiefly to the deaths reported as croup and diphtheria in the following comparisons. Also, for convenience, the series of five consecutive quinquennial periods from 1870 to 1894 is generally employed rather than single years. Rates of the average deaths in each period, carefully computed from the mean population, are used, not the means of the annual rates. Since only .4 per cent. of decedents from croup were over 20 years of age, and only about 3.5 per cent. of those from diphtheria exceeded 20 years, we shall be justified in grouping all decedents aged 20 years or over together, analysis by quinquennial periods of age being confined to decedents under 20 years of age. ratios.
We accordingly have four consecutive five-year poriods, viz., $0-4,5-9,10-14$, and 15-19, the study of which is practically exhaustive for the causes of death under consideration. Indeed, it will be found that so few deaths are reported for croup above the age of 10 years, that only the data referring to the first two quinquennial periods are of value in the discussion of this disease.

TABLE 3.-Showing, for the twenty-five-year period, 1870-94, in Michigan: 1. the percentage of deaths, by sex, at certain periods of age, as returned from croup, membranous croup and diphtheria; 2 the death rates per 100,000 population of same age and sex from each disease; 3 , the ratios

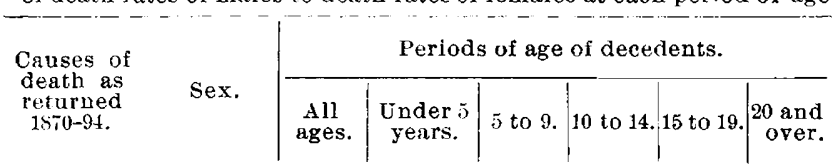

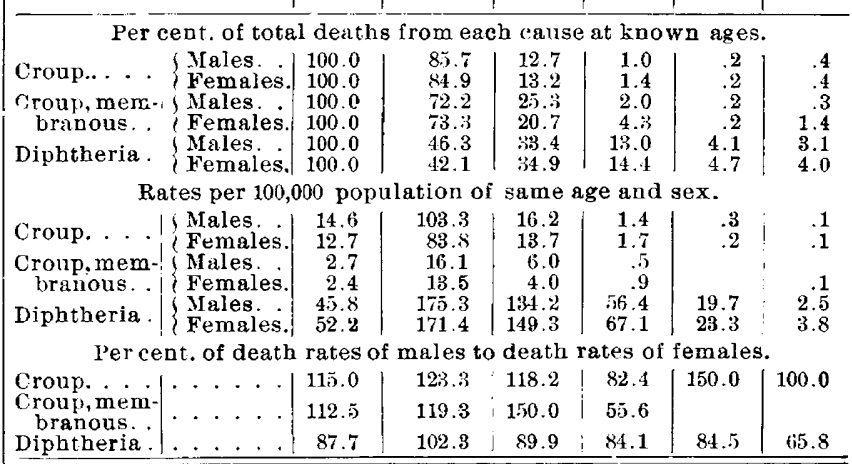

Sex incidence of diphtheria and of croup by years and quinquennicil periods.-Sex incidence at all ages is shown in Table 4 for diphtheria, croup and membranous croup. Individual years are given as well as the results for quinquennial periods. With the exception of a single year, 1873, the death rates of males from diphtheria are lower than those of females; with five exceptions, 1874, 1884, 1889, 1893 and 1894, the contrary is true for croup. From the small numbers involved, the relations of the mortality of the sexes from membranous croup may be expected to present less uniformity, but on the whole the death rates of males are greater, as with croup reported without further specification.

In the last two columns of this table the ratios of death rates of males to death rates of females from diphtheria and from croup are stated, the death rates of the females being taken as a basis ( 100.0 per cent.) in each case. This form of expression, which eliminates the error incident to comparison of deaths of males and deaths of females as returned without allowance for relative numbers of each sex in the population, will also be used in Table 5 for comparing the relative mortality of the sexes from each disease at the different age periods. It will be called, for convenience of reference, the relative male mortality. (See upper part of diagram.)

The relative male mortality from croup was slightly higher during the last quinquennial period than during the first; it rose rapidly from 1870-74 to 1875-79, declined nearly as quickly as it rose for the next two periods, and rose again from $1885-89$ to $1890-94$. The relative male mortality from diphtheria fell slightly from 1870-74 to $1875-79$, but has risen since that time. It must be remembered that these statements refer solely to the quinquennial periods as a whole; within these periods are many minor oscillations in the opposite direction to that of the general tendency of the 
By age periods, it will be noted that the curve of croup, 0-4, corresponds very closely to the relative male mortality of croup at all ages, as should evidently be the case, since about 85 per cent. of all decedents from croup were under 5 years of age. The relative male mortality of decedents from croup aged 5-9 may be said to exaggerate the variations of the group 0-5, rising and sinking more rapidly than the latter, but moving in the same general direction.

The relative male mortality of diphtheria for the two periods, 5-9, 10-14, corresponds closely to the relative male mortality of diphtheria at all ages. That of decedents under $\check{y}$ years of age moves in the opposite direction to that of the two following periods, but on the whole shows little variation. The age period, 15-19, as is generally the case when the aggregate number of deaths is becoming too small for reliable inferences, shows the most violent changes. The relative male mortality from diphtheria between the ages of 15 and 19, during the period 1885-89, exceeded the relative male mortality from croup at any age, something quite the reverse of the usual experience.

\begin{tabular}{|c|c|c|c|c|c|c|c|c|}
\hline \multirow{3}{*}{$\begin{array}{l}\text { Years } \\
\text { and pe- } \\
\text { riods. }\end{array}$} & \multicolumn{6}{|c|}{ Death rates per 100,000 population, by sex. } & \multirow{2}{*}{\multicolumn{2}{|c|}{$\begin{array}{l}\text { Per cent. of } \\
\text { death rates of } \\
\text { males to death } \\
\text { rates of females }\end{array}$}} \\
\hline & \multicolumn{2}{|c|}{ Diphtheria. } & \multicolumn{2}{|c|}{$\begin{array}{l}\text { Membranous } \\
\text { Croup. }\end{array}$} & \multicolumn{2}{|c|}{ Croup. } & & \\
\hline & Males, & $\begin{array}{l}\text { Fe- } \\
\text { males. }\end{array}$ & Males. & $\begin{array}{c}\text { Fe- } \\
\text { males. }\end{array}$ & Males. & $\begin{array}{c}\text { Fe- } \\
\text { males. }\end{array}$ & $\begin{array}{l}\text { Diph- } \\
\text { therial. }\end{array}$ & Croup. \\
\hline 1870 . & 9.1 & 11.5 & .3 & .2 & 11.5 & 9.4 & 79.1 & 122.3 \\
\hline 1871. & 8.3 & 11.6 & .8 & .3 & 12.2 & 11.8 & 71.6 & 105.2 \\
\hline 1872 . & 13.4 & 18.0 & .9 & .7 & 13.1 & 11.0 & 74.4 & 119.1 \\
\hline 1873. & 17.1 & 16.6 & .9 & & 14.2 & 11.3 & 103.0 & 125.7 \\
\hline 1874 . & 15.5 & 17.0 & .9 & 6 & 9.6 & 10.2 & 91.2 & 94.1 \\
\hline 1875 . & 15.0 & 15.8 & 1.2 & 1.3 & 12.8 & 9.5 & 94.9 & 134.7 \\
\hline 1876. & 21.4 & 24.3 & 1.2 & 1.8 & 12.8 & 8.9 & 88.1 & 143.8 \\
\hline 1875 & 38.5 & 41.8 & 1.3 & 1.3 & 10.9 & 8.5 & 92.1 & 128.2 \\
\hline $1878^{\circ}$ & 49.3 & 67.4 & 2.5 & 2.3 & 14.1 & 11.7 & 73.1 & 120.5 \\
\hline 1879 . & $8 \overline{7} .8$ & 101.6 & 2.2 & 3.6 & 17.7 & 11.3 & 84.4 & 156.6 \\
\hline 1880 & 86.3 & 103.0 & 4.1 & 3.9 & 17.2 & 14.1 & 83.8 & 122.0 \\
\hline 1881. & 115.8 & 128.9 & 4.4 & 3.1 & 21.3 & 15.7 & 89.8 & 135.7 \\
\hline 1882 . & 73.1 & 90.1 & 3.2 & 2.1 & 19.9 & 14.5 & 81.1 & 137.2 \\
\hline 1883. & 52.8 & 59.4 & 2.9 & 2.9 & 16.3 & 15.2 & 88.9 & 107.2 \\
\hline 1884 & 51.5 & 64.0 & 2.5 & 1.8 & 14.6 & 16.3 & 80.5 & 89.6 \\
\hline 1885. & 50.6 & 61.2 & 2.8 & 2.0 & 15.8 & 14.9 & 82.7 & 106.0 \\
\hline 1886 . & 54.6 & 61.3 & 5.6 & 5.1 & 15. .3 & 15,3 & 89.1 & 100.0 \\
\hline 1887. & 45.9 & 49.0 & 6.6 & 5.2 & 15.4 & 13.1 & 93.7 & 117.6 \\
\hline 1888. & 35.4 & 36.4 & 4.4 & 4.6 & 20.3 & 17.7 & 97.3 & 114.7 \\
\hline 1889. & 40.1 & 42.7 & 1.8 & 2.8 & 16.1 & 18.7 & 93.9 & 86.1 \\
\hline 1890 : & 57.1 & 64.2 & 3.5 & 1.8 & 22.3 & 17.1 & 88.9 & 1304 \\
\hline 1891. & 491 & 50.5 & 1.6 & 1.7 & 12.0 & 11.7 & 97.2 & 102.6 \\
\hline 1892. & 46.6 & 47.5 & 3.7 & 3.6 & 11.4 & 8.0 & 98.1 & 112.5 \\
\hline 1893. & 39.5 & 47.8 & 1.9 & 1.9 & 9.7 & 10.0 & 82.6 & 97.0 \\
\hline 1894. & 27.1 & 30.3 & 2.1 & 1.8 & 5.8 & 6.4 & 89.4 & 90.6 \\
\hline $1870-74$. & 12.8 & 15.0 & .8 &. .4 & 12.1 & 10.7 & 85.3 & 113.1 \\
\hline $1875-79$ & 43.2 & 51.6 & 1.7 & 1.9 & $13 . \overline{7}$ & 10.0 & 83.7 & 137.0 \\
\hline $1880-84$. & 75.1 & 88.2 & 3.4 & 2.7 & 17.8 & 15.2 & 85.1 & 117.1 \\
\hline $1885-89$. & 45.2 & 19.9 & 4.2 & 3.9 & 16.6 & 16.0 & 90.6 & 103.8 \\
\hline $1890-94$. & 47.8 & 43.7 & 2.6 & 2.2 & 12.1 & 10.5 & 91.4 & 115.2 \\
\hline $1870-94$. & 45.8 & 52.2 & 2.7 & 2.4 & 1.4 .6 & 12.7 & $8 \pi .7$ & 115.0 \\
\hline
\end{tabular}

Age incidence of diphtheria and of croup by quinquennial periods. - In the first part of Table 5 the ratios of deaths by sex, to total deaths at all ages from diphtheria and from croup are shown, for each of the quinquennial age periods studied, at each of the fiveyear periods of registration lying between 1870 and 1894. (See second part of diagram.) It will be observed that the lines representing the sexes are nearly parallel, thus showing that the influence exerted by the factor of sex at each age period is very nearly constant. The only exceptions to this rule are croup, $0-4$, for the period 1875-79, and diphtheria, ó-9, during the last quinquennial period of registration, 1890.94.
The ratio of mortality from croup under 5 years of age to total mortality from croup at all ages is nearly double that from diphtheria at the same or at any other age period. Its course is nearly uniform, and averages about $8 \tilde{o}$ per cent. for both sexes.

The curves representing the proportional mortality from diphtheria at the periods 5-9 and 10-14 are nearly parallel, and show a slight increase between the two most recent quinquennial periods. Both rose from $1870-74$ to $1875-79$, continued nearly stationary from $1875-79$ to $1880-84$, and declined together from $1880-84$ to $1885-89$. It is evident that the curve representing the proportional mortality from diphtheria in children under $\tilde{5}$ years of age must exhibit changes of a compensatory character, that is to say, as appears after examination of the figures, the ratio of decedents from diphtheria aged $0-4$ fell from $1870-74$ to $1875-79$, remained nearly stationary from $1875-79$ to $1880-84$, rose from 1880-84 to $1885-89$, and fell again from $1885-89$ to $1890-94$.

TABLE 5 .- Showing, by sex, the proportional deaths, death rates per 100,000 like population and ratios of death rates of males to death rates of females, at ceriain periods of age, from diphtheria and from croup according to the returns in Michigan during five quinquennia periods, $1870-94$.

\begin{tabular}{|c|c|c|c|c|c|c|c|}
\hline \multirow[b]{2}{*}{$\begin{array}{c}\text { Five- } \\
\text { year } \\
\text { periods. }\end{array}$} & \multirow[b]{2}{*}{$\begin{array}{l}\text { Causes of death } \\
\text { as returned. }\end{array}$} & \multirow[b]{2}{*}{ Sex. } & \multicolumn{5}{|c|}{ Periods of age of decedents. } \\
\hline & & & $\begin{array}{c}\text { Under } \\
5 \\
\text { years. }\end{array}$ & $\begin{array}{c}5 \\
\text { to } \\
y\end{array}$ & $\begin{array}{l}10 \\
\text { to } \\
14\end{array}$ & $\begin{array}{l}15 \\
\text { to } \\
19\end{array}$ & $\begin{array}{c}20 \\
\text { and } \\
\text { over. }\end{array}$ \\
\hline \multicolumn{8}{|c|}{ Per cent. of total deaths from each cause at known ages. } \\
\hline \multirow{4}{*}{$1870-74}$. & & $\left\{\begin{array}{l}\text { Males. } \\
\text { Females. }\end{array}\right.$ & $\begin{array}{l}88.1 \\
86.8\end{array}$ & $\begin{array}{l}10.9 \\
11.9\end{array}$ & .8 & & $\begin{array}{l}.3 \\
.3\end{array}$ \\
\hline & Diphtberia. . & Males. & 56.4 & 28.3 & 7.6 & 2.6 & 5.0 \\
\hline & $\theta^{2}$ & Sales. & $\begin{array}{l}49.8 \\
83.5\end{array}$ & $\begin{array}{l}33.9 \\
13.9\end{array}$ & $\begin{array}{r}10.9 \\
1.9\end{array}$ & 2.7 & $\begin{array}{r}3.1 \\
.8\end{array}$ \\
\hline & $\{$ Croup. . & Females. & 85.2 & 12.2 & 2.0 & 20 & .6 \\
\hline \multirow{2}{*}{$1875-79}$. & ( Diphtheria. & Females. & 39 & 35.7 & 15.6 & 4.5 & 4.3 \\
\hline & S Croup. . & $\left\{\begin{array}{l}\text { Males. } \\
\text { Females. }\end{array}\right.$ & $\begin{array}{l}86.0 \\
82.3\end{array}$ & $\begin{array}{l}12.7 \\
16.2\end{array}$ & $\begin{array}{r}.7 \\
1.4\end{array}$ & .1 & 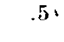 \\
\hline \multirow[t]{3}{*}{$1880-8 t$} & Dinhther & Males. & 46.3 & 33.2 & 14.1 & 3.9 & 2.5 \\
\hline & & & $\begin{array}{l}41.0 \\
85.5\end{array}$ & $\begin{array}{l}35.6 \\
12.9\end{array}$ & $\begin{array}{r}15.4 \\
1.1\end{array}$ & 5.3 & 2.7 \\
\hline & & ales. & 85.4 & 12.9 & 1.1 & & 6 \\
\hline \multirow{2}{*}{$1885-89 \ldots$} & Diphtheria & Males. & $\begin{array}{l}47.8 \\
44.9\end{array}$ & 32.4 & $11 . \overline{3}$ & 5.2 & 3.3 \\
\hline & $(0$ & Males. & 86.1 & 12.4 & .9 & .4 & $\begin{array}{r}7.0 \\
.1\end{array}$ \\
\hline \multirow[t]{2}{*}{$189 \mathrm{C}-91}$. & & Fen & $\begin{array}{l}8.5 .7 \\
43.0\end{array}$ & 11.6 & $\begin{array}{r}2.0 \\
13.8\end{array}$ & .6 & .2 \\
\hline & & & 41.1 & 34.5 & 14.4 & 4.2 & 5.7 \\
\hline
\end{tabular}

Rates per 100,000 population of the same age and sex.

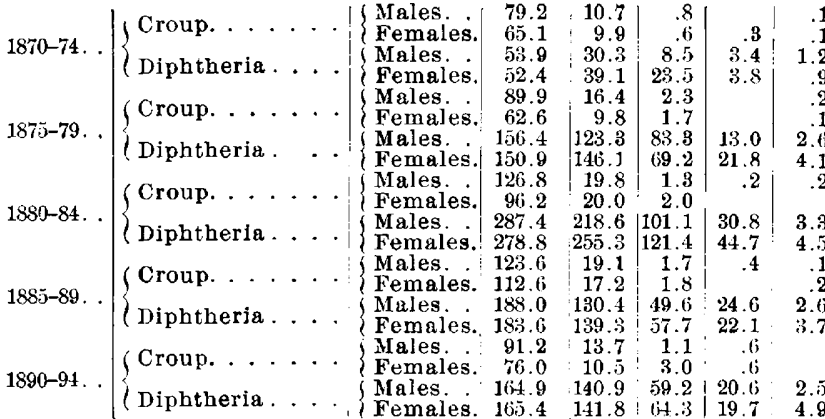

Per cent. of death rates of males to death rates of females.

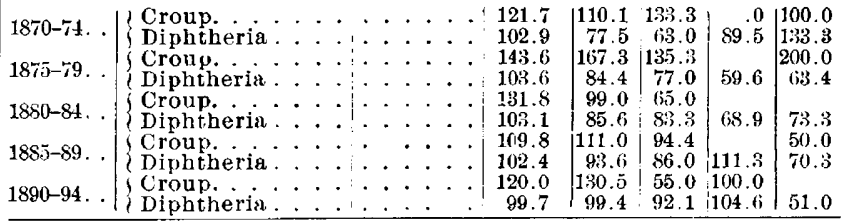

Relations of age and sex incidence of diphtheria and croup to their epidemic prevalence in Michigan. - Having considered separately the principal features of the changes in age incidence and sex incidence of diphtheria and of croup as manifested in the stastistics of successive quinquennial periods of years, it will be 
GRAPHIC ANALYSIS OF MORTALITY IN MICHIGAN AS RETURNEID FROM DIPHTHERIA AND FROM CROUP, BY QUINQUENNIAL PERIODS, 1870-94, WITH REFERENCE TO AGE AND SEX INCIDENCE.

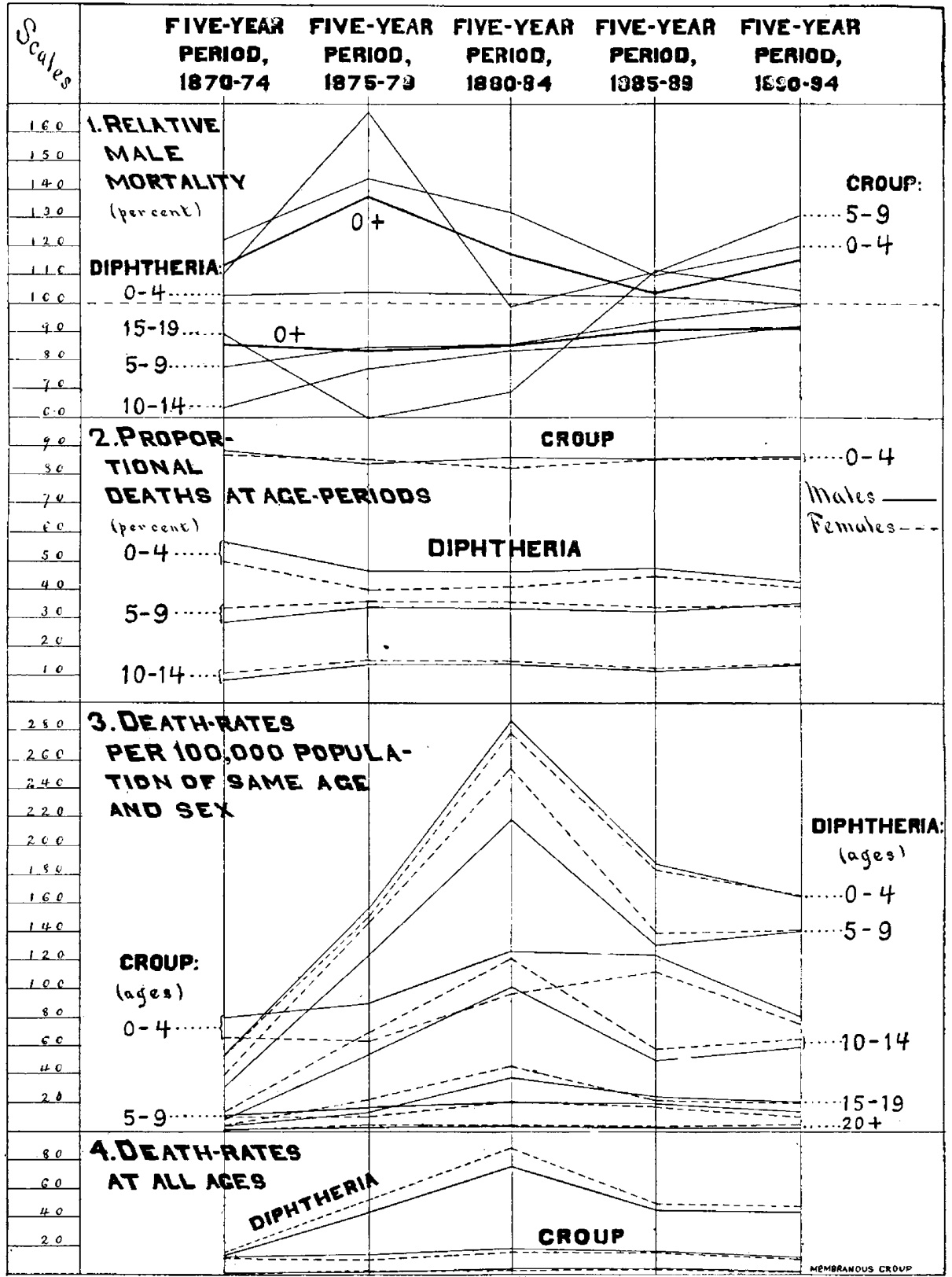

Note.-Males are indicated by a continuous line,

in all cases. Ages are both inclusive: thus 0-4 represents the five-year group ay broken line, 0 , represent all ages, etc. Beginning at the lower part of the diagram (4), death rates at all ages per 100,000 population are shown for each cause of death. These rates are further analyzed by age-periods in the part above (3), and the relations indicated in this portion of the diagram are more clearly shown with reference to sex and periods of age in parts 1 and 2 respectively. In part 1 the basis of comparison is female mortality (death-rate) taken as 100 per cent.

of interest to see what relations these changes bear to statistics of States or countries having accurate systhe variations in the death rates. For this purpose tems of registration; for this reason a supplementary the death rates from diphtheria and from croup at scale making an estimated correction (addition) of 60 the most important periods of age, and from diph- per cent. might properly have been added to the diatheria, croup, and membranous croup at all ages, are gram on the hypothesis that the percentage of defirepresented in the diagram, by sex, and may be ciency for these diseases, and for the several age directly compared with the curves showing relative periods included in them, is substantially the same as male mortality from each disease at specified age- the estimated percentage of deficiency in the returns periods, and with the curves showing the per cents of of deaths from all causes and at all ages. So far as deaths at each period of age.

the variations in mortality are concerned, ratios of

The death rates per 100,000 population according the sexes, etc., the figures represented in the diagram to the returns are, of course, too low in their absolute are probably perfectly comparable among themselves, values for purposes of comparison with corresponding $\mid$ without correction. A constant error in statistic 
data, affecting various elements uniformly, may be entirely disregarded for purposes of intrinsic comparison.

A characteristic feature of the curves representing the death rates from diphtheria is the high mortality for the period $1880-84$. In the statement by single years (Table 2) it will be seen that the maximum year was 1881, the great epidemic year for diphtheria in Michigan, for which year the number of deaths registered from this cause $(2,063)$ was greater than from any other cause of death, even consumption (1,954) being exceeded. The rise from the first period of registration, $1870-74$, to the period $1875-79$, and from the latter the period of maximum prevalence, 1880-84, was very rapid, being especially so for children at the age periods $0-4,5-9$. From $1880-84$ the death rate as a whole declined, somewhat faster than it rose, to the next period, $1885-89$, and continued nearly stationary from that to the present time. The ages 5-9 and 10-14 showed a somewhat more rapid decline from $1880-84$ to $1885-89$ than other ages, and have somewhat increased since 1885-89.

In marked contrast with diphtheria is the uniform and moderate course of croup. A slight amount of variation may, however, be noted, which is mostly in the same direction as the variations of diphtheria for the same time. Taking the age period 0.4 as especially characteristic, we see that croup increased very slightly from $1870-74$ to $1875-79$; somewhat more rapidly, but not at all approaching the virulence of diphtheria at this period, from $1875-79$ to $1880-84$; and, instead of rapidly declining like diphtheria, remained nearly stationary from $1880-84$ to $1885-89$. From $1885-89$ to $1890-94$ the death rate from croup has diminished.

The relative male mortality from croup appears to sustain a somewhat inverse relation to the general movement of the mortality from that disease. Taking the period $0-4$ years of age as typical, the relative male mortality rose noticeably from $1870-74$ to 1875 79 while the death rate increased in less degree; from $1875-79$ to 1880.84 and $1885-89$, the relative male mortality decreased while the death rate increased; from $1885-89$ to $1890-94$, the relative male mortality again rose while the death rate fell to about the same extent. Nothing very definite appears in regard to the proportional deaths from croup at this age, since the curves representing the ratios of male and female decedents move in opposite directions, and nearly neutralize each other.

The regular and nearly uniform rise of the relative male mortality of diphtheria at all ages, especially at the ages 5.9, 10.14, and the slight decline in the relative male mortality of decedents under $\tilde{5}$ years of age, when compared with the very similar mortality curves at all of these ages would seem to indicate that sex has not been an appreciable factor in the epidemic history of the disease; that is to say, variations in the extension and fatality of diphtheria have not been attended with simultaneous special increase of mortality in one sex. The change in sex incidence seems to be a general one, advancing throughout the entire history of the disease, as included in the quarter century of statistics, in a determinate direction, and perhaps dependent upon some general social change or development in the treatment of male or female children.

Age incidence, unlike sex incidence, appears to sustain a certain relation to the degree of epidemic prevalence of diphtheria. This relation is direct for the age periods $\tilde{0}-9,10-14$, and inverse for the period $0-4$. That is to say, when an increase in the general mortality from diphtheria and croup occurs, there is an increased percentage of deaths of children over 5 years of age and a decreased percentage of deaths of children under 5 years of age, as compared with the total mortality.

Dr. H. B. Baker, in a report to the Michigan State Board of Health on "The Present Comparative Immunity of Adults from Diphtheria," found that "when the reported deaths from diphtheria are over fivetenths of one death per thousand inhabitants, the average per cent. of diphtheria decedents over ten years of age is 22.55 , and when the reported deaths from diph theria are less than five-tenths of one death per thousand inhabitants, the average per cent. of diphtheria decedents over ten years of age is 19.27." This observation covered the statistics of Michigan during twenty-one years, 1868-88, for which period the mean per cent. of diphtheria decedents aged over ten years was $20.68 .^{\circ}$

Mr. Arthur Shirley, President of the Epidemiological Society, makes the following statements in regard to the changes in age incidence in England and Wales: ${ }^{10}$

"There has been throughout England and Wales relating to the diphtheria mortality at all ages a considerably augmented incidence of the disease upon the population aged above 3 and under 10 years in the decennium 1871-80, qompared with that in the decennium immediately preceding. And in the case of England and Wales as a whole, that increase has been maintained throughout the succeeding decennium 1881-90.

"When croup and diphtheria are taken together it is found that in both the periods $1871-80$ and $1881-90$ there was a relative increase of the disease at school ages (3 to 10 ) as compared with 1861-70."

Diphtheria declined in England and Wales from $1861-70$ to $1871-80$, and rose from $1871-80$ to $1881-90$. Between the two latter periods, therefore, the variation agrees with the tendency in Michigan, but the increased age incidence at older ages from $1861-70$ to 1871-80, with a decreasing death rate, differs from the observation in this State. It is possible that the difference in the exact age periods taken may in part cause this decrepancy; and that it may be due, in part, to the increased proportion of children exposed at school in England under the Education act, which went into operation in 1870.

General conclusions.-It may be well to summarize the principal indications, statistic and otherwise, which may be drawn from the study of these statistics and which are clearly shown in the accompanying diagram. It is understood that such general conclusions have reference entirely to the history of the disease in Michigan, and are of wider application only so far as confirmed by the study of the statistics of other States and countries. As there are no other statistics, however, for any State west of New England embracing the time included in the Michigan statistics, together with statements of ages of decedents from individual causes of deaths, the results presented

9 Rep. Mich. State Board of Health, 1891, p. xx.

0 Quoted by Edward Seaton. M D., in a "Report on the Present State of Knowledge Respecting the Etiology and Prevention of Diphtheria." presented on behalf of the Euglish Commitee at the Eighth Internaional Congress of Hygiene and Demography, Budapest, 1894. British Medical Journal, Sept. 15, 1894. 
in the Michigan Registration Reports will ever remain the only exact history of the course of diphtheria over any State area in the Western part of the United States during the onset and most fatal period of prevalence of the great epidemic, and as such are deserving of special study.

1. Statistically, the line of demarcation between diphtheria and croup is clearly defined. Their age incidence, their sex incidence, and, I might add, although the subject has not been studied in the present paper, their monthly and seasonal prevalence are distinct. This statistic difference is the expression of an equally well-marked clinical distinction. Even though bacteriology should decide with more certain voice than at present, that diphtheria and (nearly all) croup are identical, would it not still be advisable to keep separate the statistics of such a definitely distinguished portion of the diphtheria returns as are the deaths from "croup?" And if not the mere presence, but the predominance, of the KlebsLöffler bacillus shall come in future to be the distinguishing characteristic of true diphtheria, statisticians may awake to the fact that a great mistake has been comitted in confusing the statistics of two diseases.

2. If the statistic distinction between diphtheria and croup be maintained, the return of "membranous croup," providing it be not given a separate place as in the Michigan reports, belongs rather to croup than to diphtheria.

3 . The fact that the death rates are higher for males under 5 years of age from diphtheria, and that after that age the mortality of females from this disease is greater, is of interest, and accords with English observation. From this change in the relative mortalities, it would seem possible to derive therapeutic or prophylactic suggestions of value. What is there in the conditions attending the development of girls after the fifth year that is more favorable to fatality from diphtheria? They start out with a relative immunity, the death rate of female children under 5 years being markedly lower than that of male children at that age. Why does not this relation persist, and what causes the disease to bear more heavily upon girls than boys at the usual school age?

This question is discussed by Dr. T. W. Thompson in the article on "The Natural History of Infectious Diseases,"Stevenson and Murphy's Hygiene, vol. ii. p. 298 , but the reasons given are not intended to be considered conclusive. As embodying further the opinions of Dr. Downes and Dr. Thorne Thorne, I present his remarks in full:

"The excess of female mortality, at certain ages, at least, is no doubt largely due to greater exposure to infection-that is, to the closer and more continuous contact with the sick to which females are exposed as compared with males; but Dr. Arthur Downes has pointed to the very early ages at which the excess of female mortality is discernible as perhaps indicating that some further explanation is required. As regards this, Dr. Thorne remarks that 'the excess of diphtheria death which attaches to females over males from 3 to 15 years of age, increases precisely as the age advances which fits them more and more to take some share in the care of home, and of relations during the periods of sickness.' And he further remarks that "something may depend upon the full significance of the term 'domesticity,' and upon its taking account of those acts of affection and tenderness which, in their relation to the sick characterize females during the period of girlhood, as well as in mature womanhood.' Both these considerations are deserving of considerable weight, especially as regards a disease such as diphtheria, in the dissemination of which close contact is known to play a conspicuous part; but it still appears to remain doubtful whether increased exposure to infection can be regarded as entirely accounting for the excess of female mortality, especially in the very early years of life."

It is probable that the greater docility, affectionateness and domesticity of girls render their share of the mortality from diphtheria greater than that of boys. A larger proportion of girls may be found in regular school attendance, owing to less temptation to truancy and less liability to employment during school age. Among children girls tend, as a rule, to come into more intimate personal contact with one another. Boys naturally isolate themselves after an early age, and repulse kisses, embraces and other demonstrations of affection, as unbecoming the manly character. Besides boys indulge much more persistently in outdoor sports and occupations, and thus "toughen" themselves to resist the initial lesions of the mucous membranes, resulting, perhaps, from atmospheric irritation, which often afford a point of entrance for the diphtheria germ. Speaking of croup, but with equal application to diphtheria, Hirsch remarks: ${ }^{9}$

"Something wrong in the upbringing of the family, particularly in the way of too much tenderness and coddling, has been the real cause of the family liability. The susceptibility which predisposes to this disease would seem to be bred in those children who are kept most from the effects of the weather, sheltered from every wind, and during the cold season anxiously detained whole days and even weeks indoors, and that too, in heated and not always well-ventilated nurseries."

Whatever the cause of the greater relative female mortality from diphtheria above the age of five years, it is a cause that has been undergoing progressive amelioration during nearly the whole history of the disease in Michigan. Should the change continue at approximately the same rate, the relative death rates of the sexes will become nearly the same after the lapse of a few years. Does this indicate that the "new woman" of the future is already foreshadowed in a more masculine type of education for girlhood? At least, then, one favorable result will have to be placed to the credit of the female renaissance, if it tends to prevent diphtheria.

4. The increased proportion of mortality at ages over five years coincident with a general increased prevalence of diphtheria, has already been sufficiently pointed out. Facts of this class have an important bearing upon our knowledge of immunity, and the self-limitation of infectious diseases, but the limits of the present paper preclude any special reference to this subject.

5. Incidentally the importance of stating death rates from diphtheria and from croup in the terms of the susceptible population has been suggested. It is only in this way that the real prevalence of these diseases in countries or States with various age-distributions of population can be accurately compared. For diphtheria the number of inhabitants under 15 years of age, or if this basis were not generally obtainable,

9 Handbook of Geographical and Historical Pathology, iii, 6.5. 
the number under the age of 21 years, would give fairly accurate results; for croup, the rates should be based on the population under five years of age. In the same way that the standard distribution of ages suggested by Körösi has been adopted by the International Statistical Institute for the computation of mortality indices, instead of the unreliable death rates, for international comparisons, so should certain standard ages be selected as bases for stating all mortality rates of children's diseases; and whenever a higher mortality is shown to belong to either sex, the standard population should be stated by sex.

6. Lastly, if this paper has any predominant purpose, it is to emphasize the necessity of statistic study of diseases, and to maintain that clear-cut statistic distinctions are equally cogent with clinical or bacteriologic arguments in determining nosologic classifications. Statistics may be likened to the brake that serves to restrain the plunges of the wild horses of medical theorizing, and prevent their dragging the car of true medical science through devious ways, and to final wreck amidst a chaos of unsupported opinions. It may not be the noblest office, but it is a necessary one; and a knowledge of statistic technique should be regarded as a fundamental part of the equipment of the medical reasoner just as fully as equipment in chemic, bacteriologic, pathologic and clinical methods is deemed essential at present. Vital statistics is historically and practically the basis of an enlightened sanitary science. The statistic pictures are to be considered, in their place, equally with the clinical pictures in making up our concepts of diseases; yet from the paucity of data, especially in this country, this is very seldom done. There are very few medical colleges in the United States that give any systematic instruction in the treatment of medical statistics. The hope for the improvement of this condition lies in the spreading of a higher opinion of the services of the medical statistician among the ranks of the profession at large, and through the profession to the people. As a result of such enlightenment, accurate systems of registration will gradually come into existence in this country in all of the states whose density of population and advanced civilization may warrant them; medical schools will adequately treat the subject in their curricula, and health officers, graduated therefrom, will be able to make intelligent practical use of registration data in limiting and preventing the spread of disease; finally a vast body of the most essential facts concerning the constitution and destiny of our people will be accumulated, whose full import, vast, social significance, and practical beneficence can not be estimated in advance, but, judging from the triumphs of sanitary science based upon an exact knowledge of vital statistics in the past, will prove a potent factor in the elevation of the human race.

\section{PREVENTIVE MEDICINE IN APOPLEXY.}

Read in the Section on State Medicine, at the Forty-seventh Anuua Meeting of the American Medical Association, at Atlanta, Ga., May 5-8, 1896 .

BY EPHRAIM CUTTER, LL.D., M.D.

HARVARD, 1856; UNIVERSITY OF PENNSYLVANIA, 1857. NEW YORK.

Presuming that the Section I have the honor to address is a board of medical police whose business it is to detect the pre-stages of diseases and to procure their prevention, if not their birth, the subject is then legitimately up for thought and has an ever-present living importance. The press rarely appears without some reference to apoplexy. To-day it is Baron de Hirsch's death cabled across the Atlantic in thousands of words and eagerly read by the public who love and appreciate such wealthy nature's noblemen. The press also, with the confidence conferred by its position, affirms that champagne freely drank caused his apoplexy within a few hours. But it must have had pre-stages longer than these few hours. This idea was expressed by the late Dr. F. A. Sawyer, VicePresident Massachusetts Medical Society, who told his son that his death would be from apoplexy, as it was. My cousin, the late Dr. Calvin Cutter, author of Cutter's Physiologies, after he had experienced apoplexy accurately predicted to his son. Dr. J. Clarence Cutter, the two succeeding "strokes" he should sustain and that he would die from the third and last, which he did. If I am correctly informed, Prof. Joseph Jones, M.D., LL.D., late member of our Association, and one of the brightest medical lights of the South, if not of the age, died from apoplexy. So also died Job S. Crane of New Jersey, another A. M. A. member whose character was like pure gold, and whose presence in our meetings has added the charms of delightful friendship and genial personality in the past. If they do these things in a green tree what shall be done in the dry? If such medical men are destroyed what will be done with the laity? The high esteem of these distinguished gentlemen impels me to tell what I know personally about their disease as a grateful tribute to the lovableness and glory of their characters.

What is Apoplexy Clinically and Conventionally? - It means "sudden loss or diminution of sensation and power of voluntary motion, usually resulting from inter-cranial hemorrhage." Simple or nervous apoplexy is where no lesion is discovered. Reference is here confined to apoplexy from clot or serum pressure on or in the cerebral substance or ventricles. The chief agency lies in the rupture of an artery, usually the basilar. No rupture, no apoplexy. A normal artery will not rupture with ordinary or extraordinary heart pressure. It must be weakened beforehand. Or, in other words, there is a weakening of the artery before it ruptures.

This weakening is not due to violence of puncture by a weapon; we are not considering traumatic cases. For years it has been taught and it has been found true that this weakening comes from a substitution of the circular muscular fibers of the arteries and of the fibrous coats of capillaries, sometimes by fats or fat acids, as oil, cholesterin, lardacein, stearin and margerin, with gravelly matters as athernma, etc. The fats have not the tensile strength of muscular and fibrous tissues and hence the damage comes the moment the artery is not strong enough to resist the arterial pressure, normal or abnormal. Indeed, the artery becomes fragile like a worn-out rubber hose, which gives out where the interstitial molecular changes of the mechanical mixture of rubber and sulphur are most rapid.

The Clinical Lesion is the Fatty Degeneration.The results of the clot pressure vary from instant death to protracted paralysis more or less complete as the site of hemorrhage is nearer to or more remote from vital nerve centers. Hemorrhagic apoplexy, then, is merely a masquerade and local manifestation of fatty degeneration in the cerebral arteries and 